\title{
Prognostic value of total triiodothyronine and free thyroxine levels for the heart failure in patients with acute myocardial infarction
}

Min Gyu Kang ${ }^{1}$, Jong Ryeal Hahm² ${ }^{2}$ Kye-Hwan Kim ${ }^{1}$ Hyun-Woong Park ${ }^{1}$ Jin-Sin Koh ${ }^{1}$, Seok-Jae Hwang ${ }^{1}$, Jin-Yong Hwang ${ }^{1}$, Jong Hwa Ahn³, Yongwhi Park ${ }^{3}$, Young-Hoon Jeong 3 , Jeong Rang Park ${ }^{1}$, and Choong Hwan Kwak ${ }^{3}$

Divisions of ${ }^{1}$ Cardiology and ${ }^{2}$ Endocrinology, Department of Internal Medicine, Gyeongsang National University Hospital, Gyeongsang National University School of Medicine, Jinju; ${ }^{3}$ Division of Cardiology, Department of Internal Medicine, Gyeongsang National University Changwon Hospital, Gyeongsang National University School of Medicine, Changwon, Korea

Received: September 9, 2016 Revised : December 20, 2016 Accepted: December 25, 2016

\section{Correspondence to}

\section{Choong Hwan Kwak, M.D.}

Division of Cardiology,

Department of Internal

Medicine, Gyeongsang National

University Changwon Hospital,

Gyeongsang National University

School of Medicine, 11 Sam-

jeongja-ro, Seongsan-gu,

Changwon 51472, Korea

Tel: $+82-55-214-3720$

Fax: +82-55-214-3250

E-mail: cwakch@naver.com
Background/Aims: Although a low triiodothyronine $\left(\mathrm{T}_{3}\right)$ state is closely associated with heart failure $(\mathrm{HF})$, it is uncertain whether total $\mathrm{T}_{3}$ levels on admission is correlated with the clinical outcomes of acute myocardial infarction (AMI). The aim of this study is to investigate the prognostic value of total $\mathrm{T}_{3}$ levels for major adverse cardiovascular and cerebrovascular events (MACCEs) in patients with AMI undergone percutaneous coronary intervention (PCI).

Methods: A total of 765 PCI-treated AMI patients (65.4 \pm 12.6 years old, 215 women) between January 2012 and July 2014 were included and 1-year MACCEs were analyzed. We assessed the correlation of total $\mathrm{T}_{3}$ and free thyroxine ( $\left.\mathrm{fT}_{4}\right)$ with prevalence of 1-year MACCEs and the predictive values of total $\mathrm{T}_{3}, \mathrm{fT}_{4}$, and the ratio of total $\mathrm{T}_{3}$ to $\mathrm{fT}_{4}\left(\mathrm{~T}_{3} / \mathrm{fT}_{4}\right)$, especially for HF requiring re-hospitalization.

Results: Thirty patients (3.9\%) were re-hospitalized within 12 months to control HF symptoms. Total $\mathrm{T}_{3}$ levels were lower in the HF group than in the non-HF group $(84.32 \pm 21.04 \mathrm{ng} / \mathrm{dL}$ vs. $101.20 \pm 20.30 \mathrm{ng} / \mathrm{dL}, p<0.001)$. Receiver operating characteristic curve analysis showed the cut-offs of total $\mathrm{T}_{3}$ levels $(\leq 85 \mathrm{ng} / \mathrm{dL})$ and $\mathrm{T}_{3} / \mathrm{fT}_{4}(\leq 60)$ for $\mathrm{HF}$ (area under curve $[\mathrm{AUC}]=0.734, p<0.001 ; \mathrm{AUC}=0.774, p<0.001$, respectively). In multivariate analysis, lower $\mathrm{T}_{3} / \mathrm{fT}_{4}$ was an independent predictor for 1-year HF in PCI-treated AMI patients (odds ratio, 1.035; 95\% confidential interval, 1.007 to $1.064 ; p=0.015$ ).

Conclusions: Lower levels of total $\mathrm{T}_{3}$ were well correlated with 1-year HF in PCI-treated AMI patients. The $\mathrm{T}_{3} / \mathrm{fT}_{4}$ levels can be an additional marker to predict HF.

Keywords: Triiodothyronine; Heart failure; Acute myocardial infarction; Prognosis

\section{INTRODUCTION}

In cardiovascular systems, triiodothyronine $\left(\mathrm{T}_{3}\right)$ increases heart rate, myocardial contractility, and cardiac output. It also decreases systemic vascular resistance and improves diastolic relaxation $[1,2]$. The concentration of thyroid hormones can be deranged and affect homeostasis in individuals with severe illness. Generally, the active free $\mathrm{T}_{3}$ levels are blunted and reverse $\mathrm{T}_{3}$ levels are increased by inhibition of normal type 1 deiodinase or reduced clearance of reverse $\mathrm{T}_{3}$. This altered thyroid hormonal status due to poor general condition has been 
named "non-thyroidal illness syndrome (NTIS)" or "euthyroid sick syndrome" $[1,3]$.

Among various acute or chronic illnesses related to NTIS, heart failure (HF) and acute myocardial infarction (AMI) have been well known conditions. Although the lowering $\mathrm{T}_{3}$ is commonly interpreted as adaptive and beneficial in acute stage of the conditions, the persistently lasting low $\mathrm{T}_{3}$ levels might contribute to the progressive deterioration of cardiac function and myocardial remodeling process [4]. Iervasi et al. [5] reported that low serum $\mathrm{T}_{3}$ levels in admitted subjects with various cardiac problems reflect the severity and prognosis of cardiovascular diseases and were correlated with poor clinical outcomes. To the best of our knowledge, only a few studies $[3,6,7]$ reported on the predictive values of the levels of thyroid hormones including reverse $\mathrm{T}_{3}$ for a prognosis of patient with AMI treated with percutaneous coronary intervention (PCI). However, the measurement of reverse-form of $\mathrm{T}_{3}$ is a costly and time-consuming method in clinical practice. In this retrospective cohort study, we aimed to evaluate the levels of total $\mathrm{T}_{3}$ and free thyroxine ( $\mathrm{fT}_{4}$ ) at arrival to emergency department (ED) in 765 PCI-treated AMI patients and investigate the prognostic value of the hormonal status for 1-year major adverse cardiovascular and cerebrovascular events (MACCEs), especially HF requiring re-hospitalization.

\section{METHODS}

\section{Patients}

We retrospectively evaluated 987 AMI patients who had been admitted to the cardiac intensive care unit at Gyeongsang National University Hospital, Korea, between January 2012 and July 2014. Patients were eligible if they were $\geq 18$ years of age with ST-segment elevation AMI and non-ST elevation AMI by significant coronary artery stenosis treated with PCI. The diagnosis and treatment of patients were based on the current American College of Cardiology/American Heart Association guidelines for the management of patients with ST elevation myocardial infarction and non-ST-segment elevation acute coronary syndrome [8]. We excluded patients with AMI by vasospasm. For this study, 145 patients were excluded because of thyroid disease; who had been treated with previous or current thyroid diseases, and who were suspected thyroid disease with extremely abnormal thyroid hormone levels (thyroid stimulating hormone [TSH], > $9 \mathrm{mU} / \mathrm{L}$; or $\mathrm{fT}_{4},>3.0 \mathrm{ng} / \mathrm{dL}$ ) [3]. During follow-up period, 77 patients dropped out because of no follow-up information. Institutional Review Board approval was obtained by the local ethics committee and informed consent was waived.

\section{Biochemical investigation}

Blood sampling for biochemistry including thyroid hormone and brain natriuretic peptide (BNP) was performed as soon as the patients arrived at the ED. All patients had baseline levels of thyroid hormone including total $\mathrm{T}_{3}, \mathrm{fT}_{4}$, and $\mathrm{TSH}$ determined using an Elecsys electrochemiluminescent immunoassay (Roche Diagnostics Ltd., Mannheim, Germany). The reference ranges for our laboratory were total $\mathrm{T}_{3}$ (80 to $200 \mathrm{ng} / \mathrm{dL}$ ), $\mathrm{fT}_{4}$ (0.93 to $1.70 \mathrm{ng} / \mathrm{dL}$ ), and TSH (0.27 to $4.2 \mathrm{mU} / \mathrm{L}$ ). BNP was measured by Elecsys electrochemiluminescent immunoassay (Roche Diagnostics Ltd., Basel, Switzerland). Other biochemical measurements including creatinine, cardiac specific enzyme (creatine kinase-MB, troponin I), and lipid profile were also evaluated. Glomerular filtration rate $\left(\mathrm{mL} / \mathrm{min} / 1.73 \mathrm{~m}^{2}\right)$ was calculated by the Modification of Diet in Renal Disease formula.

\section{Coronary angiography}

All eligible patients underwent coronary angiography (CAG) and PCI as coronary reperfusion therapy. CAG was performed by standard technique and significant coronary artery disease was diagnosed visually if luminal diameter narrowing $\geq 50 \%$ was present in a major epicardial coronary artery. Left main trunk disease was counted as two-vessel disease and the presence of more than two significant coronary artery diseases was considered multivessel disease.

\section{Echocardiography}

Echocardiographic assessment was conducted within 24 hours of admission. We measured echocardiographic parameters according to current guidelines of the American Society of Echocardiography. The left ventricular ejection fraction (LVEF) was measured using modified Simpson's method. As the parameter of left ventricular diastolic function, a ratio of mitral inflow $\mathrm{E}$ velocity of 
mitral annular tissue E' velocity (E/E') were calculated. The mean value of septal and lateral E' was used for AMI patients having regional wall motion abnormalities. The right ventricular systolic pressure (RVSP) was assumed using the peak velocity of tricuspid regurgitation and inferior vena cava.

\section{Clinical outcomes}

Follow-up clinical data of 765 PCI-treated AMI patients were obtained from the following sources: reviewing the patients' hospital medical records, periodically examining the patients on outpatient clinics, and interviewing the patients via telephone. We analyzed the prevalence of 1-year MACCEs, defined as re-hospitalization for HF, nonfatal myocardial infarction or severe angina for coronary revascularization, ischemic cerebrovascular accident, and cardiac death within 12 months. In present study, the definition of cardiac death required the documentation of significant arrhythmia or cardiac arrest, death attributable to congestive HF or myocardial infarction in the absence of any other precipitating factors.

\section{Statistical analysis}

Results for continuous variables are given as the mean \pm standard deviation, whereas results for categorical variables are presented as frequencies and percentages. Comparisons between continuous variables were made using Student $t$ test. Comparisons between categorical variables were evaluated using Fisher exact test or Pearson chi-square test, as appropriate. We generated receiver operating characteristic (ROC) curves to define the optimal cut-offs of total $\mathrm{T}_{3}$ and $\mathrm{T}_{3} / \mathrm{fT}_{4}$ ratio for predicting $\mathrm{HF}$, and the area under curve (AUC) and its associated 95\% confidence interval (CI) were assessed using Medcalc version 13.3.3.0 statistical software (Medcalc, Ostend, Belgium). AUC comparison between categorical variables, high BNP and low $\mathrm{T}_{3} / \mathrm{fT}_{4}$, was performed using Medcalc statistical software. Survival analysis for clinical outcome was performed by Kaplan-Meier curve. Variables with $p<0.1$ were then entered into the multivariate logistic regression analysis providing odds ratio and $95 \%$ CI. A $p<0.05$ was considered to indicate a significant difference. All statistical analyses were performed using the SPSS version 21.0 (IBM Co., Armonk, NY, USA).

\section{RESULTS}

\section{Baseline characteristics and thyroid hormone levels}

A total of 765 PCI-treated AMI patients (65.4 \pm 12.6 years old, 215 women) were included (Fig. 1). The 143 patients (18.7\%) experienced MACCEs for 1-year. The prevalence of 1-year HF requiring re-hospitalization was 3.9\% (30 patients) and that of in-hospital and 1-year death caused by cardiac disease was $6.8 \%$ ( 52 patients). In this study, in-hospital cardiac mortality comprised the majority (47 patients, 90.3\%) of cardiac death after AMI and pump failure was the main reasons for in-hospital cardiac death. Five patients experienced cardiac death after discharge, three patients were revisit emergency room because of sudden cardiac death, one patient died from late stent thrombosis, and one patient expired due to progressive hypoxemia from intractable HF. We dichotomized into two groups, the HF or non-HF group, and compared the characteristics (Table 1). Compared to those in the non-HF group, the patients in the HF group were older $(72.1 \pm 12.4$ years vs. $65.1 \pm 12.6$ years, $p=0.030)$ and had predominance of females $(53.3 \%$ vs. 27.1\%, $p=0.020$ ). The initial-presented Killip classes and BNP levels, as well-known markers of HF of AMI, were significantly different in the two groups. The angiographic results, whether multivessel or infarct related artery disease, were not different in the two groups. In echocardiographic parameters, the baseline LVEF of the HF group were lower than those of the non-HF group

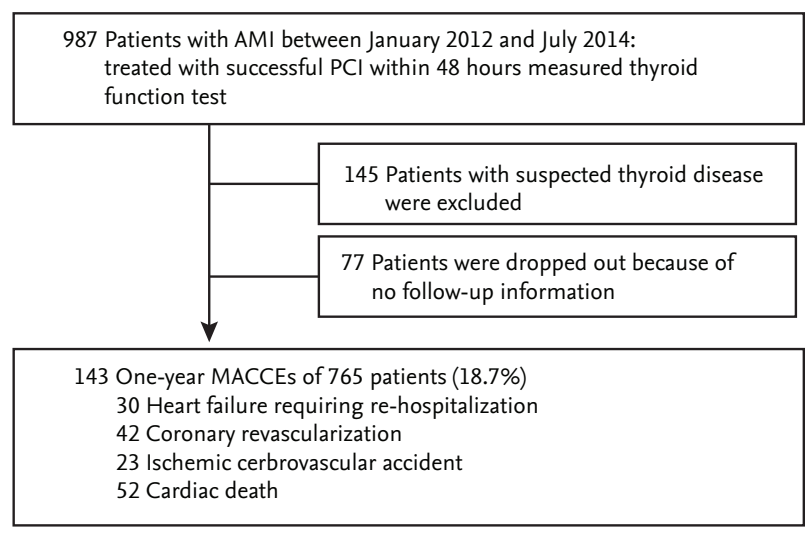

Figure 1. Study population. AMI, acute myocardial infarction; PCI, percutaneous coronary intervention; MACCEs, major adverse cardiovascular and cerebrovascular events. 
Table 1. Baseline characteristics of patients

\begin{tabular}{|c|c|c|c|}
\hline Variable & HF group $(n=30)$ & Non-HF group $(\mathrm{n}=735)$ & $p$ value \\
\hline \multicolumn{4}{|l|}{ Clinical characteristic } \\
\hline Age, yr & $72.1 \pm 12.4$ & $65.1 \pm 12.6$ & 0.030 \\
\hline Female sex & $16(53 \cdot 3)$ & $199(27.1)$ & 0.020 \\
\hline Body mass index, $\mathrm{kg} / \mathrm{m}^{2}$ & $22.9 \pm 3.8$ & $23 \cdot 9 \pm 3 \cdot 3$ & 0.088 \\
\hline \multicolumn{4}{|l|}{ Risk factors } \\
\hline Hypertension & $19(63.3)$ & $342(46.5)$ & 0.071 \\
\hline Diabetes mellitus & $12(40.0)$ & $205(27.9)$ & 0.150 \\
\hline Hypercholesterolemia & $5(16.7)$ & $182(24.8)$ & 0.307 \\
\hline Current smoking & $7(23.3)$ & $321(43.7)$ & 0.027 \\
\hline \multicolumn{4}{|l|}{ Past medical history } \\
\hline Ischemic heart disease & $6(20)$ & $104(14.1)$ & 0.371 \\
\hline Heart failure & $1(3.3)$ & $4(0.5)$ & 0.063 \\
\hline Revascularization & $4(13 \cdot 3)$ & $63(8.6)$ & 0.366 \\
\hline Ischemic stroke & $3(10.0)$ & $32(4.4)$ & 0.147 \\
\hline Chronic kidney disease & $4(13 \cdot 3)$ & $16(2.2)$ & $<0.001$ \\
\hline $\mathrm{SBP}, \mathrm{mmHg}$ & $120.9 \pm 28.9$ & $131.8 \pm 34.1$ & 0.085 \\
\hline $\mathrm{DBP}, \mathrm{mmHg}$ & $69.1 \pm 24.9$ & $76.6 \pm 22.2$ & 0.068 \\
\hline Heart rate, beats/min & $83.4 \pm 24.1$ & $73.4 \pm 20.3$ & 0.009 \\
\hline Killip class & & & 0.007 \\
\hline Class I & $18(60)$ & $624(84.9)$ & \\
\hline Class II & $5(16.7)$ & $22(3.0)$ & \\
\hline Class III & $2(6.7)$ & $31(4.2)$ & \\
\hline Class IV & $5(16.7)$ & $58(7 \cdot 9)$ & \\
\hline ST elevation MI & $17(56.7)$ & $322(43.8)$ & 0.959 \\
\hline \multicolumn{4}{|l|}{ Coronary angiography findings } \\
\hline Infarct related artery & & & 0.587 \\
\hline Left main & $3(10)$ & $25(3 \cdot 4)$ & \\
\hline Left anterior descending & $14(46.7)$ & $295(40.1)$ & \\
\hline Left circumflex & $8(26.7)$ & $174(23.7)$ & \\
\hline Right coronary artery & $5(16.7)$ & $241(32.8)$ & \\
\hline Multivessel disease & $15(50)$ & $394(53.6)$ & 0.698 \\
\hline \multicolumn{4}{|l|}{ Laboratory findings } \\
\hline BNP, pg/mL & $1,031.8 \pm 1,211.1$ & $200.4 \pm 431.8$ & $<0.001$ \\
\hline CK-MB, peak, ng/mL & $170.34 \pm 118.26$ & $132.71 \pm 113.28$ & 0.080 \\
\hline Troponin I, peak, ng/mL & $33.48 \pm 30.62$ & $27.84 \pm 28.67$ & 0.300 \\
\hline Total cholesterol, mg/dL & $183.2 \pm 42.1$ & $190.4 \pm 46.4$ & 0.402 \\
\hline HDL-C, mg/dL & $51.5 \pm 15.5$ & $44.80 \pm 13.1$ & 0.007 \\
\hline LDL-C, mg/dL & $113.5 \pm 37.0$ & $125.9 \pm 41.7$ & 0.108 \\
\hline Triiodothyronine, ng/dL & $84.32 \pm 21.04$ & $101.20 \pm 20.30$ & $<0.001$ \\
\hline $\mathrm{TSH}, \mathrm{mIU} / \mathrm{L}$ & $2.22 \pm 1.50$ & $1.78 \pm 1.19$ & 0.051 \\
\hline Free thyroxine, ng/dL & $1.43 \pm 0.28$ & $1.28 \pm 0.22$ & 0.001 \\
\hline $\mathrm{GFR}, \mathrm{mL} / \mathrm{min} / 1.73 \mathrm{~m}^{2}$ & $44.8 \pm 23.9$ & $73.9 \pm 30.9$ & $<0.001$ \\
\hline \multicolumn{4}{|l|}{ Echocardiography findings } \\
\hline LVEF, \% & $41.9 \pm 10.0$ & $53.5 \pm 8.4$ & $<0.001$ \\
\hline Mean E/E' & $13.4 \pm 5.0$ & $10.4 \pm 4.3$ & $<0.001$ \\
\hline RVSP, mmHg & $36.6 \pm 9.4$ & $28.8 \pm 8.5$ & $<0.001$ \\
\hline
\end{tabular}

Values are presented as mean \pm SD or number (\%).

HF, heart failure; SBP, systolic blood pressure; DBP, diastolic blood pressure; MI, myocardial infarction; BNP, brain natriuretic peptide; CK-MB, creatine kinase MB; HDL-C, high density lipoprotein cholesterol; LDL-C, low density lipoprotein cholesterol; TSH, thyroid stimulating hormone; GFR, glomerular filtration rate; LVEF, left ventricular ejection fraction; E/E', mitral inflow E velocity of mitral annular tissue E’ velocity; RVSP, right ventricular systolic pressure. 
$(41.9 \% \pm 10.0 \%$ vs. $53.5 \% \pm 8.4 \%, p<0.001)$ and the levels of mean E/E' and assumed RVSP were higher in the HF group than in the non-HF group (Table 1). The patients in the HF group had lower total $\mathrm{T}_{3}$ levels and higher $\mathrm{fT}_{4}$ levels $(84.32 \pm 21.04 \mathrm{ng} / \mathrm{dL}$ vs. $101.20 \pm 20.30 \mathrm{ng} / \mathrm{dL}, p$ $<0.001 ; 1.43 \pm 0.28 \mathrm{ng} / \mathrm{dL}$ vs. $1.28 \pm 0.22 \mathrm{ng} / \mathrm{dL}, p=0.001$, respectively) than those in the non-HF group (Table 1 ). Similarly, with 1-year HF, the total $\mathrm{T}_{3}$ levels were significantly lower in the patients who had experienced ischemic cerebrovascular accident, cardiac death, and all MACCEs (Fig. 2). The total $\mathrm{T}_{3}$ levels showed a tendency to be lower in patients with 1-year revascularization compared to in patients without. Contrary to total $\mathrm{T}_{3}$, the $\mathrm{fT}_{4}$ levels were only correlated with HF among MACCEs (data not shown).

\section{Predictive values of thyroid hormone levels}

The ROC curve analysis showed that the cut-off values of total $\mathrm{T}_{3}$ for predicting the 1-year HF was $\leq 85 \mathrm{ng} / \mathrm{dL}$ (AUC, $0.734 ; 95 \%$ CI, 0.701 to $0.765 ; p<0.001$ ). The sensitivity, specificity, negative predictive value, and positive predictive value were $67 \%, 78 \%, 98 \%$, and $11 \%$, respectively. In order to reflect the $\mathrm{fT}_{4}$ change, we assessed the $\mathrm{T}_{3} / \mathrm{fT}_{4}$ as one of prognostic parameters. The cut-off val- ue of $\mathrm{T}_{3} / \mathrm{fT}_{4}$ for predicting the 1-year HF was calculated as $\leq 60$ (AUC, $0.774 ; 95 \%$ CI, 0.743 to 0.803 ; $p<0.001$ ) (Fig. 3). The predictive values of HF were slightly augmented by using a composite marker, $\mathrm{T}_{3} / \mathrm{fT}_{4}$, compared to a single marker, total $\mathrm{T}_{3}$ level (sensitivity $60 \%$, specificity $87 \%$, negative predictive value $98 \%$, positive predictive value $16 \%$ ). In patients with $\mathrm{T}_{3} / \mathrm{fT}_{4} \leq 60$, the incidence of 1-year HF was higher (15.5\% vs. 1.8\%, p<0.001) (Fig. 4). There were trend of higher 1-year cardiac mortality in patients with $\mathrm{T}_{3} / \mathrm{fT}_{4} \leq 60$ (10.3\% vs. 5.7\%, $\left.p=0.060\right)$. We evaluated whether the $\mathrm{T}_{3} / \mathrm{fT}_{4}$ was an independent parameter for prediction of 1-year HF requiring re-hospitalization using multivariate logistic regression analysis. Among statistically significant parameters $(p<0.010)$ on univariate analysis, higher BNP, lower LVEF, and lower $\mathrm{T}_{3} / \mathrm{fT}_{4}$ were independent predictors (Table 2). The Killip class and mean E/E' were not significant in multivariate analysis. The total $\mathrm{T}_{3}$ level and the $\mathrm{T}_{3} / \mathrm{fT}_{4}$ levels were also a significant predictor for all MACCEs additional to BNP level. Multivariate analysis for all MACCEs showed similar results with 1-year HF (Table 3). However, for all MACCEs, AUC of $\mathrm{T}_{3}$ was larger than that of $\mathrm{T}_{3} / \mathrm{fT}_{4}$ (AUC, 0.683; 95\% CI, 0.634 to 0.731 for $\mathrm{T}_{3}$ ) (AUC, 0.647 ; 95\% CI, 0.595 to 0.699 for $\left.\mathrm{T}_{3} / \mathrm{fT}_{4}\right)$. $\mathrm{T}_{3} / \mathrm{fT}_{4} \leq 60$ was showed the
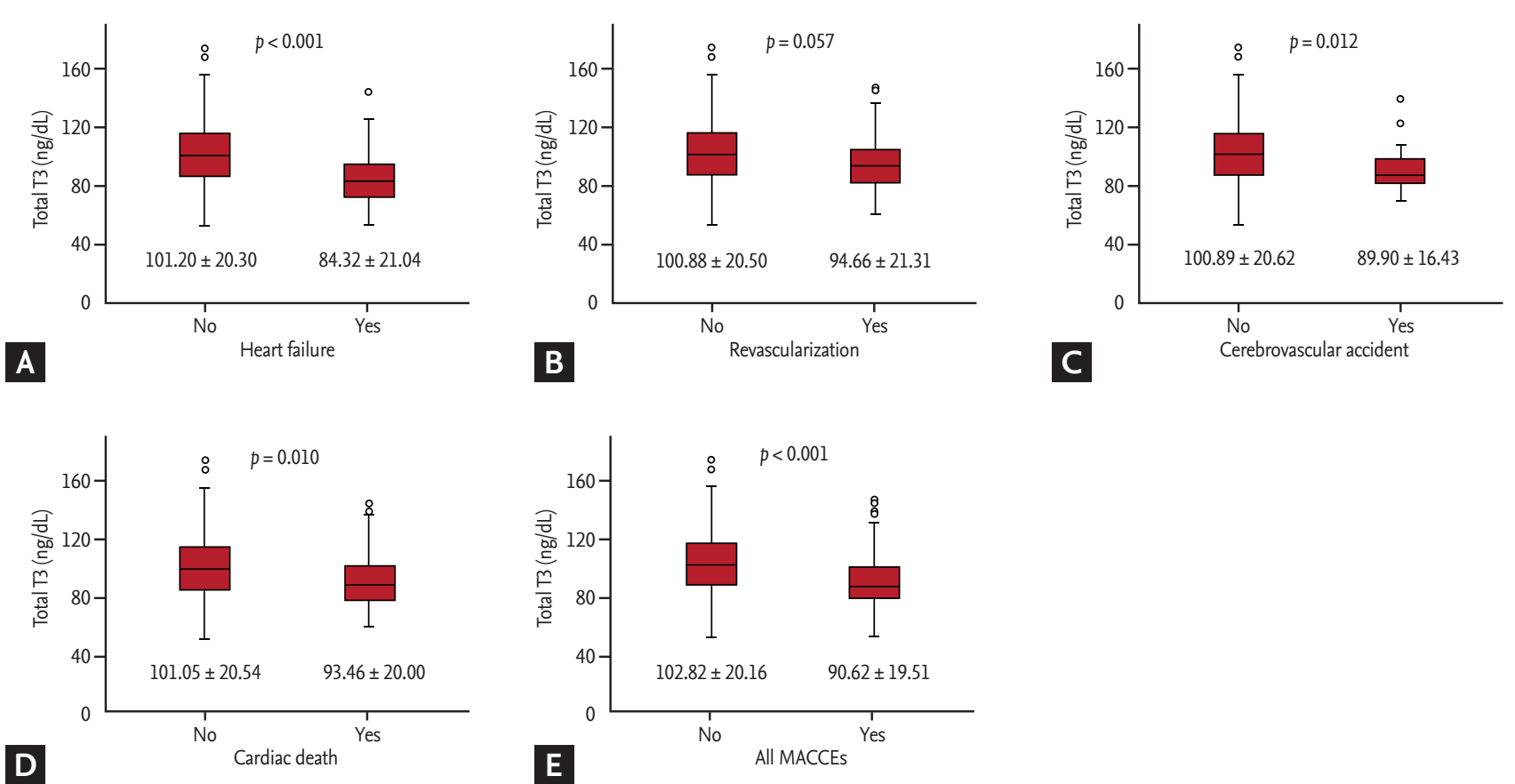

Figure 2. Comparison of total triiodothyronine $\left(\mathrm{T}_{3}\right)$ levels according to major adverse cardiovascular and cerebrovascular events (MACCEs). (A) Heart failure. (B) Revascularization. (C) Cerebrovascular accident. (D) Cardiac death. (E) All MACCEs. 

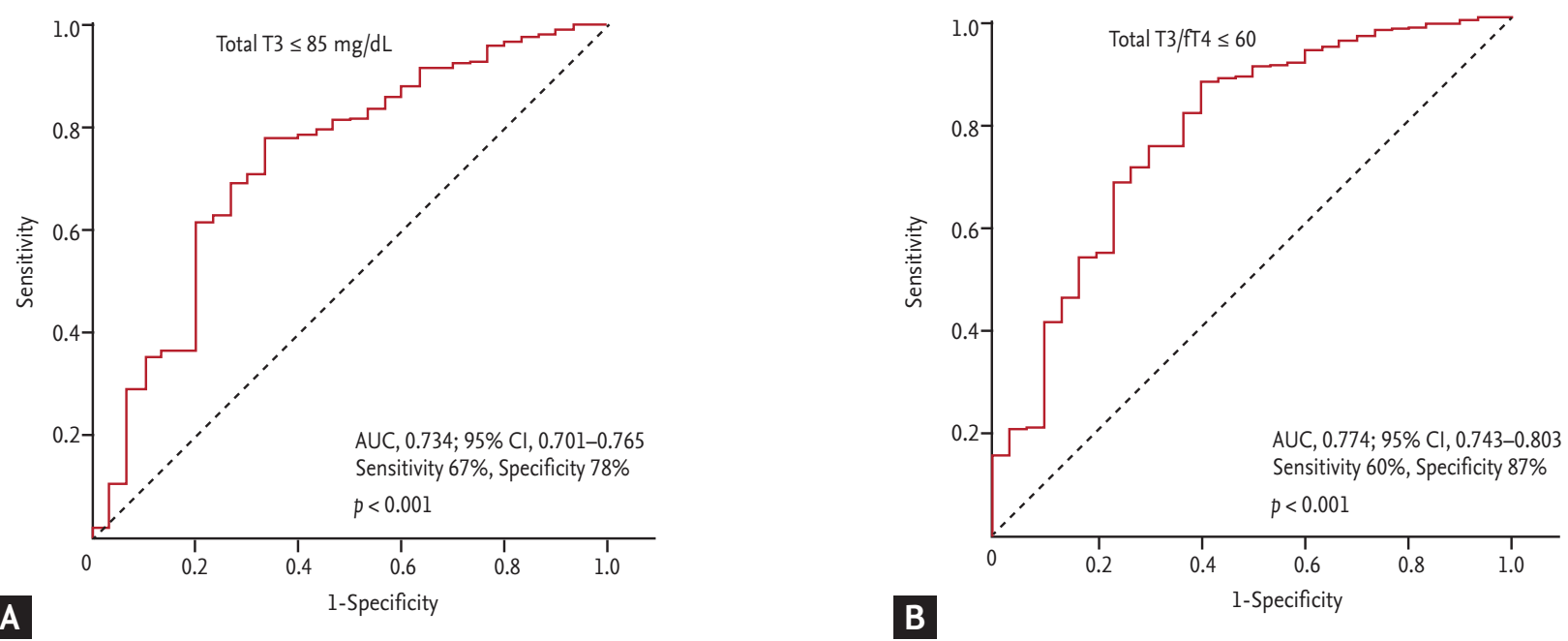

Figure 3. Cut-off values of thyroid hormone level to predict 1-year heart failure requiring re-hospitalization. (A) Total triiodothyronine ( $\mathrm{T}_{3}$ ) level. (B) Ratio of total $\mathrm{T}_{3}$ to free thyroxine ( $\left.\mathrm{fT}_{4}\right)$. AUC, area under curve; CI, confidence interval.

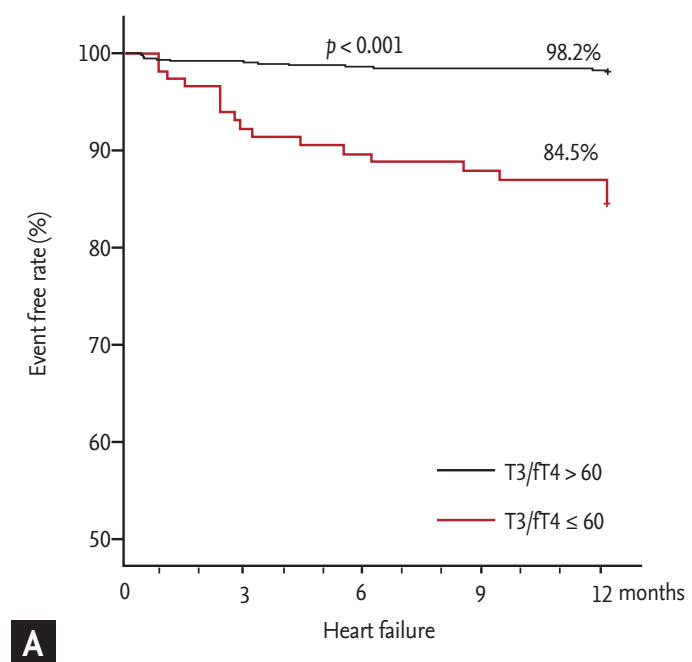

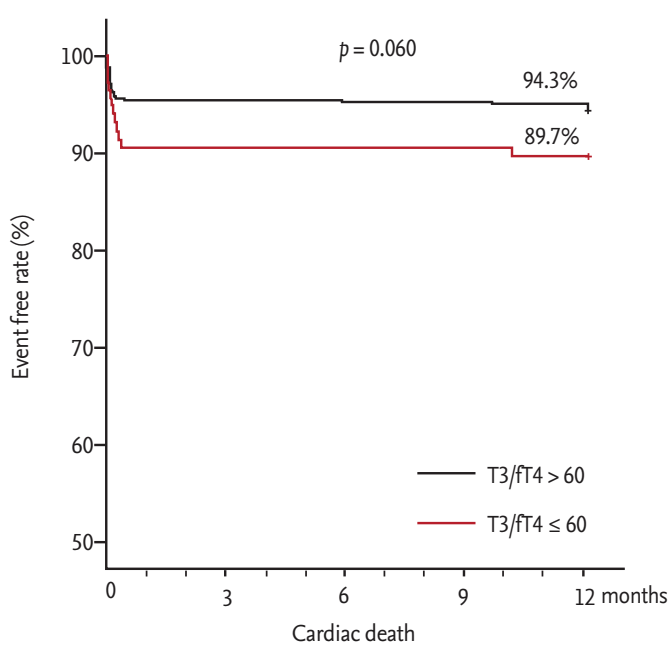

B

Figure 4. Comparison of 1-year event free rate according to thyroid hormone level. (A) Heart failure. (B) Cardiac death. T3, triiodothyronine; $\mathrm{fT}_{4}$, free thyroxine.

additive value to $\mathrm{BNP}(>123 \mathrm{pg} / \mathrm{mL})$ in ROC curve analysis (AUC, $0.818 ; p<0.001$ for BNP) (AUC, $0.865 ; p=0.015$ for $\mathrm{T}_{3} / \mathrm{fT}_{4}$ combined with BNP) (Fig. 5). As a result, low $\mathrm{T}_{3} / \mathrm{fT}_{4}$ and high BNP had most powerful predictive value for 1-year HF in patients with AMI.

\section{DISCUSSION}

In this study, we found the following: (1) the decrease in total $\mathrm{T}_{3}$ levels began at an early phase after AMI; (2) total $\mathrm{T}_{3}$ levels immediately after arrival at the ED could be practically useful predictors of 1-year MACCEs, especially $\mathrm{HF}$ requiring re-hospitalization in AMI patients with treated PCI; and (3) a $\mathrm{T}_{3} / \mathrm{fT}_{4}$ was a more helpful marker than total $\mathrm{T}_{3}$ for prediction of 1-year HF.

NTIS is frequently found in various acute and chronic serious systemic conditions without evidence of pre-existing disease of the hypothalamic-pituitary-thyroid (HPT) axis. The low $\mathrm{T}_{3}$ and elevated reverse $\mathrm{T}_{3}$ are 
Table 2. Univariate and multivariate analysis to predict the 1-year heart failure requiring re-hospitalization

\begin{tabular}{|c|c|c|c|c|}
\hline \multirow{2}{*}{ Variable } & \multicolumn{2}{|c|}{ Univariate analysis } & \multicolumn{2}{|c|}{ Multivariate analysis } \\
\hline & Odds ratio $(95 \% \mathrm{CI})$ & $p$ value & Odds ratio $(95 \% \mathrm{CI})$ & $p$ value \\
\hline Age, /yr & $1.049(1.015-1.083)$ & 0.003 & $0.999(0.953-1.047)$ & 0.963 \\
\hline Female sex & $3.076(1.474-6.410)$ & 0.002 & $1.567(0.568-4.326)$ & 0.386 \\
\hline SBP & $0.992(0.983-1.001)$ & 0.085 & - & - \\
\hline Heart rate & $1.024(1.006-1.042)$ & 0.008 & - & - \\
\hline Killip class & $1.483(1.097-2.005)$ & 0.007 & $0.894(0.551-1.452)$ & 0.651 \\
\hline $\log _{10} B N P$ & $10.811(5.246-22.277)$ & $<0.001$ & $3.004(1.191-7.576)$ & 0.020 \\
\hline Total $\mathrm{T}_{3}$ & $0.956(0.936-0.976)$ & $<0.001$ & - & - \\
\hline $\mathrm{fT}_{4}$ & $11.441(2.827-46.302)$ & 0.001 & - & - \\
\hline Total $\mathrm{T}_{3} / \mathrm{fT}_{4}$ & $1.046(1.024-1.068)$ & $<0.001$ & $0.967(0.941-0.993)$ & 0.015 \\
\hline LVEF & $1.124(1.083-1.168)$ & $<0.001$ & $0.891(0.840-0.944)$ & $<0.001$ \\
\hline Mean E/E' & $1.098(1.038-1.161)$ & 0.001 & $0.963(0.882-1.052)$ & 0.406 \\
\hline GFR & $1.039(1.023-1.054)$ & $<0.001$ & $0.989(0.968-1.011)$ & 0.989 \\
\hline
\end{tabular}

CI, confidential interval; SBP, systolic blood pressure; BNP, brain natriuretic peptide; T3, triiodothyronine; fT4, free thyroxine; LVEF, left ventricular ejection fraction; E/E', mitral inflow E velocity of mitral annular tissue E' velocity; GFR, glomerular filtration rate.

Table 3. Univariate and multivariate analysis to predict the all major adverse cardiovascular and cerebrovascular events

\begin{tabular}{|c|c|c|c|c|}
\hline \multirow{2}{*}{ Variable } & \multicolumn{2}{|c|}{ Univariate analysis } & \multicolumn{2}{|c|}{ Multivariate analysis } \\
\hline & Odds ratio $(95 \% \mathrm{CI})$ & $p$ value & Odds ratio $(95 \% \mathrm{CI})$ & $p$ value \\
\hline Age, /yr & $1.041(1.025-1.058)$ & $<0.001$ & $0.987(0.963-1.012)$ & 0.314 \\
\hline Female sex & $2.021(1.383-2.954)$ & $<0.001$ & $1.450\left(0.853^{-2.464}\right)$ & 0.170 \\
\hline Hypertension & $2.121(1.460-3.081)$ & $<0.001$ & $1.744(1.075-2.830)$ & 0.024 \\
\hline SBP & $0.982(0.976-0.987)$ & $<0.001$ & $0.995(0.986-1.003)$ & 0.204 \\
\hline Heart rate & $0.971(0.960-0.983)$ & $<0.001$ & - & - \\
\hline Killip class & $2.028(1.710-2.404)$ & $<0.001$ & $1.112(0.833-1.485)$ & 0.470 \\
\hline $\log _{10} B N P$ & $3.300(2.361-4.613)$ & $<0.001$ & $1.759(1.091-2.835)$ & 0.020 \\
\hline Total $\mathrm{T}_{3}$ & $0.969(0.959-0.978)$ & $<0.001$ & - & - \\
\hline $\mathrm{fT}_{4}$ & $1.705(0.781-3.721)$ & 0.180 & - & - \\
\hline Total $\mathrm{T}_{3} / \mathrm{fT}_{4}$ & $0.973(0.964-0.983)$ & $<0.001$ & $0.982(0.968-0.995)$ & 0.008 \\
\hline LVEF & $0.940(0.920-0.961)$ & $<0.001$ & $0.975(0.947-1.003)$ & 0.074 \\
\hline Mean E/E' & $1.077\left(1.035^{-1.120}\right)$ & 0.001 & $0.994(0.943-1.048)$ & 0.821 \\
\hline GFR & $0.979(0.969-0.983)$ & $<0.001$ & $0.990(0.979-1.001)$ & 0.073 \\
\hline
\end{tabular}

CI, confidential interval; SBP, systolic blood pressure; BNP, brain natriuretic peptide; $\mathrm{T}_{3}$, triiodothyronine; $\mathrm{fT}_{4}$, free thyroxine; LVEF, left ventricular ejection fraction; E/E', mitral inflow E velocity/mitral annular E' velocity; GFR, glomerular filtration rate.

the most prominent alterations of early phase of acute NTIS. The pathophysiological mechanism of NTIS involves two closely related processes, inflammation, and oxidative stress. Firstly, severe illness accompanying inflammation leads to increased cytokines such as inter- leukin 6, which suppresses the HPT axis. In addition, the inflammatory cytokines also change deiodinases expression and their activities resulting in decreased $\mathrm{T}_{3}$ and elevated reverse $\mathrm{T}_{3}$ concentrations at the plasma and cellular levels $[4,9]$. 


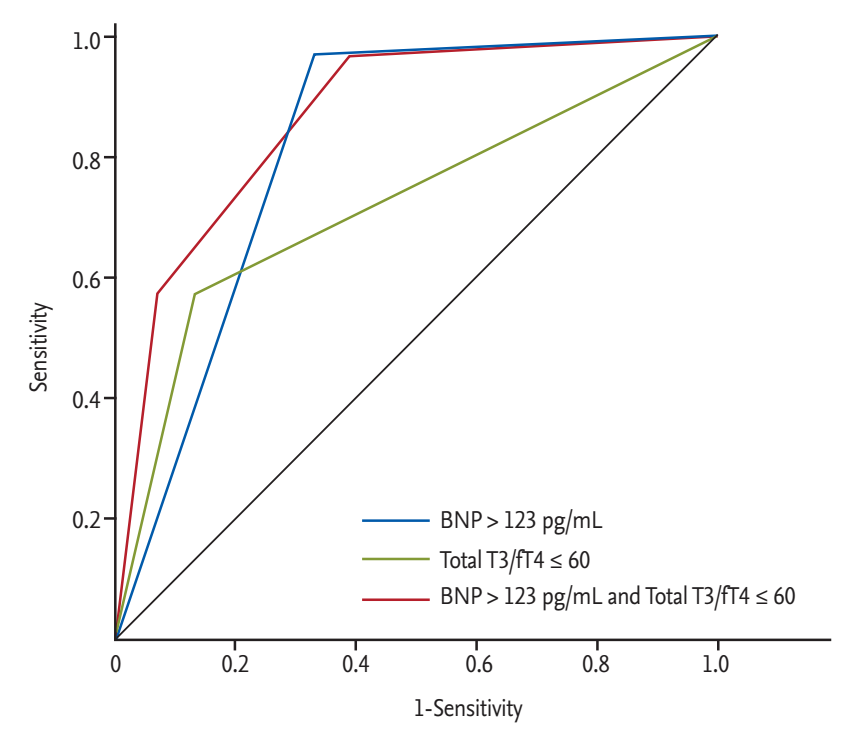

\begin{tabular}{|l|c|c|c|c|c|}
\hline & Sensitivity, \% & Specificity, \% & AUC & $95 \% \mathrm{Cl}$ & $p$ value \\
\hline BNP $>123 \mathrm{pg} / \mathrm{mL}$ & 96.4 & 67.3 & 0.818 & $0.788-0.845$ & Reference \\
\hline Total T3/fT4 $\leq 60$ & 60.0 & 86.7 & 0.720 & $0.686-0.752$ & $0.041^{\mathrm{a}}$ \\
\hline $\begin{array}{l}\mathrm{BNP}>123 \mathrm{pg} / \mathrm{mL} \\
\text { and total } \mathrm{T} 3 / \mathrm{fT} 4 \leq 60\end{array}$ & 61.3 & 96.4 & 0.865 & $0.838-0.889$ & $\begin{array}{c}0.015^{\mathrm{a}} / \\
<0.001^{\mathrm{b}}\end{array}$ \\
\hline
\end{tabular}

Figure 5. Comparison of area under curve (AUC) to predict the 1-year heart failure requiring re-hospitalization. BNP, brain natriuretic peptide; $\mathrm{T}_{3}$, triiodothyronine; $\mathrm{fT}_{4}$, free thyroxine; CI, confidence interval. ${ }^{\mathrm{a}}$ Comparison with BNP level (reference value), ${ }^{\mathrm{b}}$ Comparison with thyroid hormone level.

Although the low $\mathrm{T}_{3}$ by both decreased $\mathrm{D}_{1}$ and $\mathrm{D}_{2}$ activities and induced $\mathrm{D}_{3}$ activation is beneficial for reduction of energy turnover and oxygen consumption, tissue hypothyroidism could cause further oxidative stress, leading to a vicious cycle [4]. In cardiovascular system, thyroid hormone decreases vascular resistance, activates the renin-angiotensin-aldosterone system, and increases blood volume, consequently increasing cardiac contractility and cardiac output $[1,2]$. The NTIS, low T3 state, is associated with worsened systolic and diastolic heart function [10-13]. Additionally, thyroid hormones have a role of angiogenesis in myocardium; low $\mathrm{T}_{3}$ state deteriorates pathologic remodeling process and HF progression [14]. Therefore, tissue hypothyroidism via vicious cycle can result in poor cardiovascular outcomes including mortality.

Several studies have reported about NTIS in subjects with AMI [3,6,7,10]. In AMI condition, decrease of free $\mathrm{T}_{3}$ and increase of reverse $\mathrm{T}_{3}$ have been documented $[15,16]$. In animal models, Ojamaa et al. [17] showed that low $\mathrm{T}_{3}$ levels fell within 1 week of AMI and remained $>40 \%$ lower than those in controls 4 weeks after AMI. Olivares et al. [18] also reported that reduced $\mathrm{T}_{3}$ levels were low until 8 weeks post-AMI. In patients with AMI, $\mathrm{T}_{3}$ changes occur rapidly within 12 hours from the onset of symptoms, reaching a nadir by 72 hours. This early $T_{3}$ change was related to the extent of myocardial damage using wall motion score index and cardiac specific enzyme, creatinine kinase and troponin-I [10,19]. There were some reports that thyroid hormone is predictable of poor outcomes using free $\mathrm{T}_{3}$ levels and reverse $\mathrm{T}_{3}$ levels. However, there were only a few reports using total $\mathrm{T}_{3}$ levels $[3,10]$. The report by Lymvaios et al. [10] showed that total $\mathrm{T}_{3}$ levels initially obtained were decreased and the total $\mathrm{T}_{3}$ levels at 48 hours were correlated with recovery of LVEF. Comparing the two groups by increased $\operatorname{LVEF}(\geq 5 \%)$ or not-increased $\operatorname{LVEF}(<5 \%)$, the initial total $\mathrm{T}_{3}$ levels were low and significantly different between the two groups at 24 hours. In the current study, an initial lower total $\mathrm{T}_{3}$ level was significantly correlated with poorer outcomes, and was consistent with findings of previous studies. Furthermore, our study enrolled AMI patients who had undergone PCI. In current practice, almost all AMI patients are treated with PCI at arrival for chest pain. Therefore, our results may be more compatible to the real-world scenario, and could exclude the effects of coronary reperfusion. Therefore, we suggest that total $\mathrm{T}_{3}$ levels rapidly decline from very early phase in AMI patients with serious stress state. Furthermore, the decreased $\mathrm{T}_{3}$ levels continue for several weeks and the chronic NTIS influences poor outcomes including mortality and HF aggravation.

This study revealed that $\mathrm{fT}_{4}$ levels were elevated after AMI. Almost previous observations on predictive value of thyroid hormones showed that the changes of $\mathrm{fT}_{4}$ were very small and insignificant compared to $\mathrm{T}_{3}$ levels. In contrast, other reports, such as that of Friberg et al. [3], showed that the elevated $\mathrm{fT}_{4}(>15 \mathrm{pmol} / \mathrm{L})$ group has higher mortality, although this was not statistically significant in the multivariate model. The thyroid hormones obtained at the time of admission were similar our study [3]. As shown those finding, the $\mathrm{fT}_{4}$ elevation can observe very transiently in early phase of acute illness without significant change of $\mathrm{T}_{4}$-binding globulin levels. This phenomenon might be explained by the following mechanisms: decreased conversion of $\mathrm{T}_{4}$ to 
T3 due to a decreased D1 activity [20], reduced serum $\mathrm{T}_{4}$ binding affinity due to the presence of a dissociable competitive $\mathrm{T}_{4}$ binding inhibitor in the serum [21], and reduced hepatic clearance of $\mathrm{T}_{4}[\mathbf{2 2 , 2 3}]$. We can hypothesize that these changes in patients with AMI would be prominent in more serious condition. Here, we thought that changes of $\mathrm{fT}_{4}$ can strengthen the prognostic value of total $\mathrm{T}_{3}$ levels and showed that $\mathrm{T}_{3} / \mathrm{f}_{4}$ was a more helpful marker to predict the HF requiring re-hospitalization than a single total $\mathrm{T}_{3}$ levels. Furthermore, lower $\mathrm{T}_{3} / \mathrm{fT}_{4}$ levels had high specificity to predict the 1-year HF after AMI. To the best of our knowledge, this is the first study on $\mathrm{T}_{3} / \mathrm{fT}_{4}$ levels as a predictable marker. We believe that easily measurable total $\mathrm{T}_{3}, \mathrm{fT}_{4}$, and their ratio can be used to predict the individualized prognosis of patients with AMI in clinical practice, especially in ED.

There are some limitations in the present study. First, this is retrospective study. We could not evaluate the chronicity of cardiovascular disease, especially chronic $\mathrm{HF}$, and all comorbidities. The $\mathrm{T}_{3}$ levels could reflect the various diseases. For removal of this selection bias, we excluded patients with extremely abnormal range of thyroid hormone levels, during the process of collecting the past medical history and evaluating their effects. However, the multiple compound biases can still be present in this study. Second, this study does not have the profiles of reverse $\mathrm{T}_{3}$, free $\mathrm{T}_{3}$, and thyroid hormone antibodies and we did not routinely check serial total T3 levels at follow-up. Third, we did not evaluate the inflammatory markers and cytokines such as interleukin 6. Because C-reactive protein levels can be obtained from only some of the patients, a statistical analysis was impossible. Therefore, we cannot conclude the mechanism of acute alterations of $\mathrm{T}_{3}$ and $\mathrm{f}_{4}$ in patients with AMI. These problems require further investigation with large-scaled, prospective studies that incorporate serial measurements of thyroid function tests.

\section{KEY MESSAGE}

1. Lower levels of total triiodothyronine $\left(\mathrm{T}_{3}\right)$ were well correlated with 1-year major adverse cardiovascular and cerebrovascular events in percutaneous coronary intervention-treated acute myocardial infarction patients, especially heart failure (HF) requiring re-hospitalization.

2. The $\mathrm{T}_{3} /$ free thyroxine levels can be an additional marker to predict $\mathrm{HF}$.

\section{Conflict of interest}

No potential conflict of interest relevant to this article was reported.

\section{Acknowledgments}

This study was supported by the Basic Science Research Program through the National Research Foundation (NRF) of Korea funded by the Ministry of Science, ICT and Future Planning (NRF-2015R1A5A2008833) and by Development Fund Foundation, Gyeongsang National University, May 2015.

\section{REFERENCES}

1. Klein I, Ojamaa K. Thyroid hormone and the cardiovascular system. N Engl J Med 2001;344:501-509.

2. Klein I, Danzi S. Thyroid disease and the heart. Circulation 2007;116:1725-1735.

3. Friberg L, Drvota V, Bjelak AH, Eggertsen G, Ahnve S. Association between increased levels of reverse triiodothyronine and mortality after acute myocardial infarction. Am J Med 2001;111:699-703.

4. Mancini A, Di Segni C, Raimondo S, et al. Thyroid hormones, oxidative stress, and inflammation. Mediators Inflamm 2016;2016:6757154.

5. Iervasi G, Pingitore A, Landi $P$, et al. Low-T3 syndrome: a strong prognostic predictor of death in patients with heart disease. Circulation 2003;107:708-713.

6. Zhang B, Peng W, Wang C, Li W, Xu Y. A low $\mathrm{fT}_{3}$ level as a prognostic marker in patients with acute myocardial infarctions. Intern Med 2012;51:3009-3015.

7. Lazzeri C, Sori A, Picariello C, Chiostri M, Gensini GF, Valente S. Nonthyroidal illness syndrome in ST-elevation myocardial infarction treated with mechanical revascularization. Int J Cardiol 2012;158:103-104.

8. Levine GN, Bates ER, Blankenship JC, et al. 2015 ACC/ AHA/SCAI focused update on primary percutaneous coronary intervention for patients with ST-elevation myocardial infarction: an update of the 2011 ACCF/AHA/SCAI guideline for percutaneous coronary intervention and the 
2013 ACCF/AHA guideline for the management of ST-elevation myocardial infarction: a report of the American College of Cardiology/American Heart Association Task Force on Clinical Practice Guidelines and the Society for Cardiovascular Angiography and Interventions. Circulation 2016;133:1135-1147.

9. de Vries EM, Fliers E, Boelen A. The molecular basis of the non-thyroidal illness syndrome. J Endocrinol 2015;225:R67-R81.

10. Lymvaios I, Mourouzis I, Cokkinos DV, Dimopoulos MA, Toumanidis ST, Pantos C. Thyroid hormone and recovery of cardiac function in patients with acute myocardial infarction: a strong association? Eur J Endocrinol 2011;165:107-114.

11. Selvaraj S, Klein I, Danzi S, Akhter N, Bonow RO, Shah SJ. Association of serum triiodothyronine with B-type natriuretic peptide and severe left ventricular diastolic dysfunction in heart failure with preserved ejection fraction. Am J Cardiol 2012;110:234-239.

12. Ascheim DD, Hryniewicz K. Thyroid hormone metabolism in patients with congestive heart failure: the low triiodothyronine state. Thyroid 2002;12:511-515.

13. Pingitore A, Landi P, Taddei MC, Ripoli A, L'Abbate A, Iervasi G. Triiodothyronine levels for risk stratification of patients with chronic heart failure. Am J Med 2005;118:132-136.

14. Liu Y, Sherer BA, Redetzke RA, Gerdes AM. Regulation of arteriolar density in adult myocardium during low thyroid conditions. Vascul Pharmacol 2010;52:146-150.

15. Franklyn JA, Gammage MD, Ramsden DB, Sheppard MC. Thyroid status in patients after acute myocardial infarc- tion. Clin Sci (Lond) 1984;67:585-590.

16. Pimentel RC, Cardoso GP, Escosteguy CC, Abreu LM. Thyroid hormone profile in acute coronary syndromes. Arq Bras Cardiol 2006;87:688-694.

17. Ojamaa K, Kenessey A, Shenoy R, Klein I. Thyroid hormone metabolism and cardiac gene expression after acute myocardial infarction in the rat. Am J Physiol Endocrinol Metab 2000;279:E1319-E1324.

18. Olivares EL, Marassi MP, Fortunato RS, et al. Thyroid function disturbance and type 3 iodothyronine deiodinase induction after myocardial infarction in rats a time course study. Endocrinology 2007;148:4786-4792.

19. Wang WY, Tang YD, Yang M, et al. Free triiodothyronine level indicates the degree of myocardial injury in patients with acute ST-elevation myocardial infarction. Chin Med J (Engl) 2013;126:3926-3929.

20. Van den Berghe G. Non-thyroidal illness in the ICU: a syndrome with different faces. Thyroid 2014;24:1456-1465.

21. Wilcox RB, Nelson JC, Tomei RT. Heterogeneity in affinities of serum proteins for thyroxine among patients with non-thyroidal illness as indicated by the serum free thyroxine response to serum dilution. Eur J Endocrinol 1994;31:9-13.

22. Kaptein EM, Kaptein JS, Chang EI, Egodage PM, Nicoloff JT, Massry SG. Thyroxine transfer and distribution in critical nonthyroidal illnesses, chronic renal failure, and chronic ethanol abuse. J Clin Endocrinol Metab 1987;65:606-616.

23. McIver B, Gorman CA. Euthyroid sick syndrome: an overview. Thyroid 1997;7:125-132. 